\title{
Cannabis Prices on the Dark Web
}

\author{
Jakub Červený* $\quad$ Jan C. van Ours ${ }^{\dagger}$
}

August 30, 2019

\begin{abstract}
This paper examines prices of cannabis sold over the anonymous internet marketplace AlphaBay. We analyze cannabis prices of 500 listings from about 140 sellers, originating from 18 countries. We find that both listing characteristics and country characteristics matter. Cannabis prices are lower if sold in larger quantities, so there is a clear quantity discount. Cannabis prices increase with perceived quality. Cannabis prices are also higher when the seller is from a country with a higher GDP per capita or higher electricity prices. The internet based cannabis market seems to be characterized by monopolistic competition where many sellers offer differentiated products with quality variation causing a dispersion of cannabis prices and sellers have some control over the cannabis prices.
\end{abstract}

Keywords: Cannabis prices, Dark Web

JEL-codes: D43, K42

${ }^{*}$ Department of Health Economics, Center for Public Health, Medical University of Vienna; jakub.cerveny@muv.ac.at

${ }^{\dagger}$ Corresponding author: Erasmus School of Economics, Erasmus University Rotterdam and Tinbergen Institute (Amsterdam/Rotterdam), The Netherlands; Department of Economics, University of Melbourne, Parkville, Australia and CEPR (London); vanours@ese.eur.nl. 


\section{Introduction}

Drug policies around the world have been relatively strict since the adoption of the Single Convention on Narcotic Drugs in 1961. However, in recent years many countries started adopting more liberal policies towards consumption of cannabis. European countries such as Portugal, Czech Republic and Germany pursued decriminalization policies, while the Netherlands has quasi-legalized cannabis use and retail sale. In 2013, Uruguay was the first country in the world to legalize recreational cannabis use, followed by Canada in 2018. In the US, at a federal level cannabis is still illegal but several states have legalized medical cannabis use, decriminalized or even legalized recreational cannabis use. Nevertheless, recreational cannabis remains an illegal drug in many countries.

Related to the illegal nature, information and therefore studies on quality, prices and quantities of cannabis consumed or supplied are limited. Nisbet and Vakil (1972) is a pioneering work analyzing cannabis prices using self-reported data of US university students. Many studies focused on estimation of participation elasticities, i.e. the effect of prices on the extensive margin of cannabis use (see for example Pacula et al. (2001), Cameron and Williams (2001), DeSimone and Farrelly (2003), Williams (2004), Williams et al. (2004), Zhao and Harris (2004), Clements and Zhao (2009) and Clements et al. (2010)). Van Ours and Williams (2007) study the price sensitivity of cannabis use dynamics among young Australians finding that low prices stimulate the uptake of cannabis while reducing quitting from cannabis use. There are also a few studies on the supply side of the cannabis market investigating the determinants of cannabis prices.

Cannabis prices vary both between and within countries. Statistics Canada for example reported that in 2017 cannabis prices ranged from a low US $\$ 5.02$ in the province of Manito to US $\$ 7.18$ in the territories. ${ }^{1}$ These numbers are in line

\footnotetext{
${ }^{1}$ See https://www.statcan.gc.ca/
} 
with the 2018 cannabis price index that provides cannabis prices by city, where for Canada the price range in US dollars per gram was from 6.15 in Montreal to 7.82 in Toronto. ${ }^{2}$ The 2018 cannabis price index for US cities ranged from a low US $\$ 7.58$ per gram in Seattle to US $\$ 18.08$ per gram in Washington DC. The overall range in the 2018 cannabis price index was from US $\$ 1.34$ per gram in Quito (Ecuador) to US $\$ 32.66$ per gram in Tokio (Japan). ${ }^{3}$ Cannabis prices vary across countries for various reasons, i.e. differences in legal regime with respect to the consumption and/or production of cannabis, quality of the cannabis, market power of cannabis suppliers. There is also within country variation of cannabis prices for similar reasons as also within a country the legal regime may differ like for example in the US where recreational cannabis use is legalized in some states but prohibited in others.

Previous studies on the determinants of drug prices mainly focus on quantity discounts and quality effects. An early study is Brown and Siverman (1974) who analyze data of heroin prices based on purchases by US undercover narcotics agents. They find a quantity discount while purity of the heroin is found to have a positive effect on the heroin price. Caulkins and Padman (1993) analyze price data collected by US undercover narcotics agents for various illicit drugs including cannabis. They find for most drugs quantity discounts and quality premiums. Clements (2006) studies the price of cannabis using Australian data collected through undercover buys finding a quantity discount. Caulkins and Pacula (2006) use data from a US household survey to investigate the variation in cannabis prices finding a quantity discount elasticity. Lakhdar et al. (2016) ana-

\footnotetext{
${ }^{2}$ See http://weedindex.io/

${ }^{3}$ Such huge price differences are also present for heroine and cocaine. According to the UNODC (United Nations Office on Drugs and Crime), in 2016 the retail (street) price for heroine in Western and Central Europe ranged from US $\$ 24$ per gram in Belgium to US $\$ 166$ per gram in Finland whereas the average for the United States was US $\$ 152$ per gram. Similarly the retail (street) price of cocaine in the United States $\$$ per gram ranged from 59 in Belgium to 117 in Sweden with an average of 93 for the US.
} 
lyzes cannabis prices using information from regular French cannabis users finding a significant quantity discount and significant positive quality effects. Lahaie et al. (2016) study heroine prices in France using data on heroin samples and surveys of heroin users finding significant quantity discounts and positive purity effects. Smart et al. (2017) study cannabis prices of retail transactions from Washington state where cannabis sales are legal. They find are a significant quantity discount and significant positive price effects of quality.

Online illegal drug markets with cannabis transactions as an important element are a recent phenomenon. Through the so called Dark Web, sellers and buyers of cannabis interact anonymously. Soaka and Christin (2015) present a descriptive analysis of various online anonymous market places including the first successful one, Silk Road, which was online from 2011 to 2013 when it was taken down by law enforcement and its operator was arrested. They conclude that these online market places are resilient to law enforcement take-downs as within a month after shutdown 'a novel incarnation' of Silk Road was online. Van Hout and Bingham (2013) conclude on the basis of anonymous online interviews among users that transactions are experienced to be safer than negotiating in a street-level drug market. Décary-Hétu et al. (2016) study the risk-taking behavior of drug sellers at the Dark Web concluding that compared to traditional drug market transactions the risk of violence is reduced as the face-to-face transactions are eliminated. Aldridge et al. (2018) argue that online illegal markets may reduce the harm of drug use through the increase in quality and safety of the drugs sold and because in the course of the transaction there is less conflict and violence. Furthermore, it is easier to build a reputation because of customer feedback. Barratt and Aldridge (2016) argue that higher drug quality may be the most important reason for buyers to prefer transactions through the Dark Web rather than via face-to-face interactions.

Aldridge and Décary-Hétu (2016) study data of the first major internet based 
illegal market, Silk Road 1. In their analysis of more than thousand drug-selling vendors from about 40 countries, they conclude that drug sales accounted for about a quarter of the total revenue on the market, with ecstasy-type drugs dominating the wholesale activity. Bhaskar et al. (2019) in their analysis of more than 1.5 million online drug sales focus on moral hazard, analyzing seller reputation and performance. They find that only a small proportion of on line drug deals received a bad rating from buyers. For Dark Web vendors, bad ratings lead to big reductions in sales and to market exit. The authors also note that compared to street sales of illegal drugs, Dark Web marketplaces suffer less from problems of drug adulteration and low quality. According to Bhaskar et al. (2019) a substantial share of drug users buy their drugs online through the Dark Web. Duxbury and Haynie (2018) analyze the network structure of opioid distribution through the Dark Web. They arrive to similar conclusions as Bhaskar et al. (2019), finding that vendors' trustworthiness explains more variation in the overall network structure than the affordability of vendor products or the diversity of vendor product listings.

Our paper presents an analysis based on unique data on cannabis prices. Whereas usually information on cannabis prices is based on undercover operations or consumer surveys we use information from cannabis sellers. We exploit data from the Dark Web site called AlphaBay, a website that operated between December 2014 and July 2017. According to Christin (2017) during that time among the online drug market places it became the leading one. From an analysis of 27 scrapes from AlphaBay Christin (2017) concludes that half of the drug sellers specialized in one drug. From a descriptive analysis of the cannabis sales he also concludes that most transactions are for $1 \mathrm{~g}, 5 \mathrm{~g}$ and $10 \mathrm{~g}$ while there is a modest volume discounting, i.e. larger quantities are sold at a lower price.

We use data collected from AlphaBay for two weeks early October 2015. At the 
time, AlphaBay was still in its initial stage on a steep expansion curve. PaquetClouston et al. (2018) for example report about 700 vendors in the drug sections of AlphaBay end of September 2015. Five months later the number of vendors was more than doubled. ${ }^{4}$ We have information about 500 cannabis prices from about 140 sellers in 18 countries. The nature of our data allows us to exploit the detailed information about the quality of a particular cannabis strain, measured both by its potency (active ingredient content) and popularity among users. Our main contribution to the literature on the analysis of cannabis markets is threefold. First, we study the relationship between cannabis prices, quantities and qualities whereas often quality is not part of the analysis. Second, we use information from the Dark Web to provide a quantitative analysis whereas thus far mostly descriptive studies are available. Third, because our data allow us to include seller characteristics - including their country of origin - in the analysis we can investigate to what extent seller have some influence over cannabis prices.

The remainder of our paper is organized as follows. Section 2 outlines the Dark Web in relation to information about cannabis transactions. In the spectrum of drugs available through the Dark Web, cannabis is special in the sense that the legal status of the drug varies a lot. In many countries, cannabis is an illicit drug but in other countries or parts of countries (states in the US) cannabis use is legalized or quasi-legalized. Section 3 presents our data and some summary statistics. Section 4 discusses the set-up of our empirical analysis. Section 5 presents our parameter estimates and Section 6 concludes.

\footnotetext{
${ }^{4}$ Nevertheless, overall the drug transactions on the dark web are limited in value estimated to account for no more than 0.1-0.2 percent of the combined annual drug retail markets in the US and the EU (United Nations Office on Drugs and Crime (2018)).
} 


\section{The Dark Web}

\section{$2.1 \quad$ TOR software}

The advent of sophisticated cryptographic algorithms and distributed networks gave rise not only to a better privacy on the internet, but also sparked the creation of many so-called "Dark Web" websites. Thanks to The Onion Router (TOR) software, internet users are able to hide and transmit their communication anonymously. The core principle behind the TOR was developed as a project at the US Naval Research Laboratory and Defense Advanced Research Projects Agency (DARPA) in the early 1990s. Further work on the idea by mathematician Paul Syverson and computer scientists Roger Dingledine and Nick Mathewson resulted in the initial release of the software in September 2002. TOR encrypts the transmitted data in several layers (hence the name onion) operating on top of the standard TCP. ${ }^{5}$ Encrypted packets are sent through a network of randomly selected relay gateways, which are part of the standard internet. At each of these relays, only one layer of the transmitted data is being decrypted, making it therefore impossible to trace information such as the destination and the source. At the last point of the relay, the data are finally sent to the destination IP address (McCoy et al. (2008)). To access a TOR network nowadays, one only needs a TOR browser (available as open-source software). The browser is similar in its function to any other commonly used internet browser.

Since 2004, the TOR service provides anonymity not only to users, but also services such as websites. These are accessed through a special dot-onion address (otherwise similar to any standard www domain). TOR relays are capable to read and route such addresses, while at the same time hiding the real destination

\footnotetext{
${ }^{5}$ Transmission Control Protocol, responsible for transmitting the vast majority of the WorldWide Web traffic.
} 
under the dot-onion handle. Contrary to the standard internet protocols, TOR provides complete anonymity to its users and services. This feature makes it an ideal platform for many illicit activities, hence the "Dark Web".

\subsection{Dark Web sites}

The range of activities operated under the TOR network spans from fraud and scam websites to black market activities. Perhaps one of the most famous hidden services operated on the Dark Web was a site called Silk Road. Since its inception in February 2011, the site became famous for selling among others illicit drugs, weapons, credit card numbers and child pornography. Similar in its layout to eBay, users were able to advertise and sell virtually everything, without fear of being traced. Payments were made in bitcoins, the virtual currency allowing a similar degree of anonymity to both sides of the transaction. ${ }^{6}$

Silk Road quickly gained popularity among drug users, and became relatively well-known among non-drug users. This sparked interest from law enforcement. After several months of collecting evidence, the Federal Bureau of Investigation (FBI) shut-down the Silk Road servers and arrested its alleged owner in October 2013, after almost two and a half years of its operation. As Barratt et al. (2014) note, the FBI estimated the sales revenue to be 1.2 billion US dollars. Nevertheless, the second iteration of Silk Road followed soon, with promises of improved security. After a year of providing its services, "Silk Road 2.0" followed the fate of its predecessor, thanks to the successful cooperation between FBI and Europol. Soon after the incident, one of the other hidden market places changed its name to "Silk Road 3 Reloaded".

\footnotetext{
${ }^{6} \mathrm{~A}$ Bitcoin is an electronic cryptocurrency operated through a de-centralized distributed public ledger (the record of all bitcoin transactions) called a blockchain. The system works in a way that all users running Bitcoin software participate in the verification of the ledger through a network of nodes.
} 


\subsection{AlphaBay}

We use data from a Dark Web site called AlphaBay. AlphaBay began its operations on 1 September 2014, as an auction-style marketplace for all black market items. It allowed users to sell and buy items in several categories, ranging from chemicals and drugs to weapons, jewels, software and several others. The interface and functioning of AlphaBay were very similar to other auction sites, such as eBay. Registered users were allowed to advertise items for sale and buy from other sellers and also allowed auctions. In our analysis, all content included in the dataset is fixed-price only. All transactions on the marketplace were made using Bitcoin, and therefore are highly anonymous. Every user account had its own virtual wallet, where bitcoins needed to be transferred in order to engage in further transactions. AlphaBay ceased its operations after a law enforcement action in July 2017.

Registration on the marketplace was free and only required a user name and password. Upon successful creation of an account, users were able to browse the content of the market. The site also allowed search of its contents according to several criteria such as price, country of origin, and type of payment. For ease of use, all listings displayed the purchase price in US dollars, together with the respective amount in bitcoins. ${ }^{7}$

Apart from the price and quantity offered, a typical listing also displayed an image of the item for sale, together with a short description. ${ }^{8}$ For our study, the most important information supplied is the name of cannabis strain. This signals information about the quality and psychoactive effects, as the names of strains are usually well known among users. These strains are also frequently tested for their

\footnotetext{
${ }^{7}$ The site also displayed daily conversion rates from bitcoins to regular traded currencies.

${ }^{8}$ See the appendix for a screenshot of an example listing from AlphaBay. We did not exploit these screenshots in the analysis as it is difficult to transform the photographic information into a measure of quality. Also, the photographs presented are not necessarily representing the actual cannabis for sale. The sellers could have taken a general photo from internet just by way of illustration of what they offered for sale.
} 
potency and effects, both in laboratory and in festivals such as the Cannabis Cup. ${ }^{9}$ The THC content usually varies even within the same strain, depending on several factors used during production. ${ }^{10}$ Testing standards for cannabis potency also differ between laboratories. To address this issue, we collected several measurements from different sources together with the potency claimed by the seller (if available) and use an average of these values for the purpose of analysis. ${ }^{11}$ Buyers could also see the user name of the seller (vendor), country of origin and judge the reputation of the seller based on a user rating. AlphaBay allowed to provide feedback after finishing the transaction in a similar manner as eBay does. The feedback response could be either positive, neutral or negative. The resulting user rating was then displayed as the percentage of positive ratings. Furthermore, users could write a short feedback note. This allowed sellers to build a successful reputation.

There were two possible methods of payment, finalize early (FE) or escrow. Escrow payment needed to be authorized by a trusted third party, most often the site administrator. After submission of the payment, the buyer usually waited until the shipment of goods arrived before finalizing the transaction, which effectively transferred funds to the seller. If this was not the case, the buyer could ask for a refund. The system was designed to prevent scams. Certain sellers were allowed to claim an FE payment, meaning that the transaction was authorized by the buyer before the item arrived. This posed inherent risks, as in the case of a scam, the funds were impossible to retrieve. Therefore, new users were strongly discouraged

\footnotetext{
${ }^{9}$ We cannot verify to what extent the sellers are cheating with respect to the cannabis strains they offer. However, we have the impression that this is not an important issue since two-thirds of all seller-ratings are at the maximum of 100, i.e. receiving only positive ratings.

${ }^{10} \mathrm{THC}$, i.e. Tetrahydrocannabinol is the main cannabinoid psychoactive substance present in cannabis. Psychoactive effects of cannabis, also known as "high" are mainly due to the activity of THC. The effects of cannabis are subjective and vary from person to person, and include a general alteration of conscious perception, euphoria and relaxation. Upon ingestion of higher doses, negative effects such as anxiety, ataxia (lack of muscle coordination) might manifest. Therefore, cannabis with very high potency might not always be preferred by users.

${ }^{11}$ See the appendix for the list of sources for lab measurements.
} 
to engage in FE payments within the Dark Web community forums.

After submission of the order, users had to fill in the address for shipping. Although not strictly required, this was usually done in a secure way, using an encrypted message through PGP. ${ }^{12}$ Items on the AlphaBay were commonly dispatched using standard international or domestic mail services.

\section{$3 \quad$ Data and summary statistics}

Our dataset contains information about 511 cannabis prices, sold by 141 different vendors from 18 countries. ${ }^{13}$ We collected data from the "Cannabis and Hashish" subsection of the site between 29 September and 12 October 2015 that were still active. The focus of our analysis is on active listings due to the fact that the listings sold out in the past are often deleted by sellers. Paquet-Clouston et al. (2018) estimate that approximately $20 \%$ of listings on AlphaBay did not remain online for more than two weeks. For each listing, we have the following information: the fixed minimum quantity of cannabis offered per item, the claimed cannabis strain, the fixed price of the item, the number of items sold, the number of items in stock (available only for some listings), seller handle, country of origin, type of payment accepted and where the sellers ships.

Note that both the quantity and the price per item are fixed and non-negotiable. We calculate that price per gram from offered quantity and the related listed price. The quantity offered is a minimum. For example, suppose a listing offered 8 grams of cannabis for a listed price of US $\$ 80$. Then, we calculate the price as US $\$ 10$ per gram. If this listing also displayed 30 items sold, we calculate total quantity sold as $30 \times 8=240$ grams. We have no information about the total amount of items

\footnotetext{
${ }^{12} \mathrm{PGP}$ is an acronym for Pretty Good Privacy, an encryption algorithm used primarily for encryption of files, e-mails and texts.

${ }^{13}$ We include only prices for cannabis herb (also called buds). Cannabis resin (hashish) and any other products made from cannabis such as butter are excluded.
} 
sold per transaction. So, the 30 items sold could have been sold in minimum 1 transaction and maximum 30 transactions. Table 1 shows the summary statistics of our dataset.

\section{TABle 1: Summary Statistics}

\begin{tabular}{lccccc}
\hline \hline Variable & Mean & Std. Dev. & Min. & Max. & N \\
\hline Cannabis price (US \$ per g) & 10.4 & 5.6 & 1.4 & 64.0 & 511 \\
Quantity per item (g) & 94.8 & 335.5 & 0.2 & 4560.0 & 511 \\
Total quantity sold (g) & 307.2 & 929.1 & 0.0 & 7700.0 & 511 \\
Seller rating (0-100) & 98.1 & 4.6 & 69 & 100 & 511 \\
Escrow payment (0-1) & 0.75 & 0.43 & 0 & 1 & 511 \\
THC content (\%) & 16.0 & 3.3 & 1.0 & 25.0 & 503 \\
Top 3 cannabis cup (0-1) & 0.25 & 0.43 & 0 & 1 & 511 \\
Decriminalized/legal (0-1) & 0.59 & 0.49 & 0 & 1 & 511 \\
Distance to source (km) & 1617.7 & 1625.2 & 1 & 4881 & 489 \\
Electricity cost (US \$/kWh) & 19.0 & 7.6 & 7.0 & 32.0 & 486 \\
\hline
\end{tabular}

The average price per gram of dried cannabis herb was US $\$ 10.4$. The cannabis price ranged from US $\$ 1.4$ to $\$ 64$ per gram depending on the strain and quality, a.o. the THC content. The average amount of cannabis offered per listing was 88.8 gram, with the amounts ranging from 0.2 gram to more than 4.5 kilos. On average, a listing on the AlphaBay marketplace sold abut 300 grams of cannabis. The largest quantity sold was 7.7 kilogram. The site allowed its users to rate the sellers. The rating depends mainly on factors such as quality of cannabis claimed quality of cannabis received, time until the delivery of goods etc. The lowest rated seller had a score of 69 on a scale from 0 to 100, i.e. had 69 percent of the ratings being positive. Since about two-thirds only received positive scores, the average seller rating was very high, i.e. 98.2. About 75 percent of sellers accepted escrow payments, while the remaining 25 percent required to finalize the transaction early. The usual content of THC was around 16 percent. ${ }^{14}$ About 25 percent of the

\footnotetext{
${ }^{14}$ Note that this is slightly lower than the averages reported by Jikomes and Zoorob (2018)
} 
listings on the site was selling cannabis strains ranked within the top 3 of the annual Cannabis Cup event. Of all listings, around 60 percent originated from countries where cannabis use is either decriminalized, quasi-legalized or legalized. Apart from the variables listed in Table 1, we also collected the strain (name) of the herb sold, seller handle, country of origin and countries the seller shipped to.

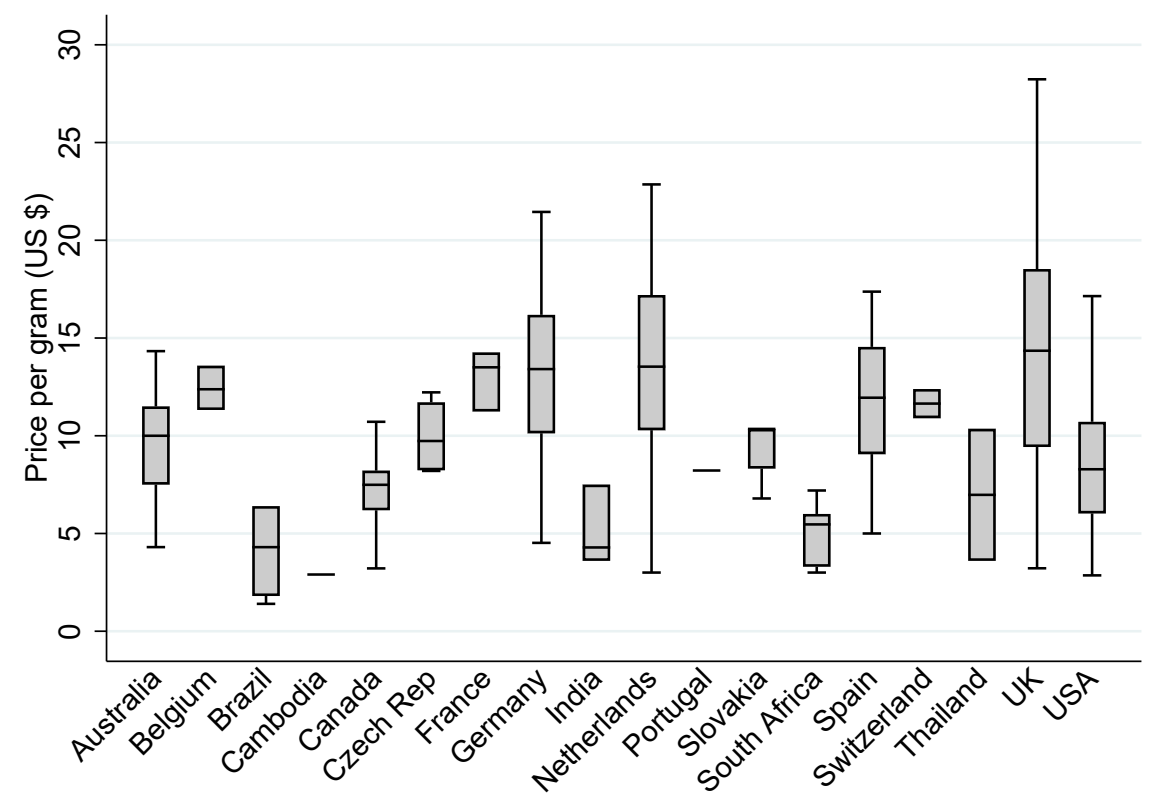

\section{Figure 1: Box Plot of Cannabis Prices by Country of Origin}

Figure 1 plots the distribution of cannabis prices for every country included in the dataset. The lowest median price of cannabis on sale in the market originated from Cambodia, at around US \$2.9. Slightly more expensive cannabis was from Brazil, where the median price was around US \$4.1. Canada, the second biggest country of origin in our dataset had a median price of around US $\$ 7.4$ per gram. Herbs around the same price could also be purchased from Thailand, with a median price of seven US dollars. Within European countries, median prices varied from and Smart et al. (2017), who report values ranging from 17.7 to 20.4 percent in the US state of Washington 
slightly more than US $\$ 8.2$ in Portugal and US $\$ 10$ in Slovakia, to around US $\$ 14.3$ in the United Kingdom. The median price of cannabis in the biggest market, the USA, was around US $\$ 8.3$ per gram.

Table 2 summarizes cannabis market statistics by country. The lowest average price offered was from Cambodia, at US $\$ 3.4$ per gram, whereas the highest price was from the UK, US $\$ 14.3$ per gram. The average price in the biggest market, the USA, was slightly more than nine US dollars per gram. The most potent cannabis herb originated from France, with an average THC content of 17 percent, followed by Canada with 16.5. The average quantity offered varies a lot from country to country. From the table it is clear that a higher average price correlates with a lower amount of cannabis offered per item. The highest average amount offered per item is by vendors from Cambodia, at an average price of little more than four dollars. At a similar price, sellers from South Africa offer slightly less than 30 grams per listing. The two biggest markets in the dataset, Canada and the USA, offer on average between 130 and 175 grams of cannabis, at an average price of seven and nine dollars respectively.

In terms of total cannabis sold, clearly the biggest market was the USA, with almost 105 kilograms of dried cannabis sold, followed by neighboring Canada with almost 30 kilograms. ${ }^{15}$ Together, these two countries accounted for almost 80 percent of the total amount of cannabis sold. The third biggest seller was India with eight kilograms. The fourth biggest seller was United Kingdom, with 2.7 kilograms. The Netherlands with its quasi-legal cannabis status sold 3.4 kilograms in total. Australia and Germany accounted for 2.4 and three kilograms of the aggregate amount sold on AlphaBay. Compared to these, the remaining countries included in the dataset sold relatively negligible amounts, accounting for approximately 10

\footnotetext{
${ }^{15}$ This amount is relatively small when compared to for example the 300,000 kilograms of cannabis sold in Colorado's regulated market during 2017; see https: //www . colorado.gov/pacific/sites/default/filesMED $\% 20$ Demand $\% 20$ and $\% 20$ Market $\% 20 \%$ 20Study $\% 20 \% 20082018$.pdf
} 
percent of the full volume.

There is also a strong correlation between GDP per capita and cannabis price. In countries such as Cambodia and India with a low GDP per capita the cannabis price was substantially lower than in a country such as Germany with a substantially higher GDP per capita.

Table 2: Market Statistics by Country

\begin{tabular}{lccccccc}
\hline \hline Country & $\begin{array}{c}\text { Average } \\
\text { price } \\
\text { (US } \$)\end{array}$ & $\begin{array}{c}\text { Average } \\
\text { potency } \\
\text { (\% THC) }\end{array}$ & $\begin{array}{c}\text { Average } \\
\text { quantity } \\
\text { offered (g) }\end{array}$ & $\begin{array}{c}\text { Total } \\
\text { quantity } \\
\text { sold (kg) }\end{array}$ & $\begin{array}{c}\text { Decrimi- } \\
\text { nalized } \\
\text { /Legal }\end{array}$ & GDP & N \\
\hline Australia & 9.9 & 16.1 & 40.5 & 2.3 & $\mathrm{I}$ & 10.7 & 41 \\
Belgium & 12.4 & 13.0 & 3.7 & 0.0 & $\mathrm{D}$ & 10.7 & 3 \\
Brazil & 4.1 & 12.5 & 31.2 & 0.0 & $\mathrm{I}$ & 9.7 & 4 \\
Cambodia & 3.4 & 12.5 & 465.0 & 0.2 & $\mathrm{D}$ & 8.1 & 5 \\
Canada & 7.4 & 16.5 & 131.6 & 28.4 & $\mathrm{D}$ & 10.7 & 77 \\
Czech Rep & 10.0 & 16.2 & 4.1 & 0.1 & $\mathrm{D}$ & 10.3 & 4 \\
France & 13.0 & 17.0 & 13.3 & 0.3 & $\mathrm{I}$ & 10.6 & 3 \\
Germany & 14.5 & 15.7 & 16.8 & 2.2 & $\mathrm{I}$ & 10.7 & 42 \\
India & 5.1 & 12.5 & 29.3 & 8.2 & $\mathrm{D}$ & 8.7 & 3 \\
Netherlands & 14.2 & 16.0 & 16.3 & 3.4 & $\mathrm{~L}$ & 10.8 & 33 \\
Portugal & 8.2 & 16.0 & 10.0 & 0.0 & $\mathrm{D}$ & 10.2 & 2 \\
Slovakia & 9.2 & 15.0 & 4.2 & 0.0 & $\mathrm{I}$ & 10.2 & 5 \\
South Africa & 5.1 & 14.2 & 26.6 & 1.2 & $\mathrm{I}$ & 9.5 & 6 \\
Spain & 11.8 & 16.0 & 4.8 & 0.1 & $\mathrm{~L}$ & 10.4 & 2 \\
Switzerland & 11.6 & 14.5 & 9.8 & 0.3 & $\mathrm{D}$ & 11.0 & 2 \\
Thailand & 7.0 & 12.5 & 13.8 & 0.2 & $\mathrm{I}$ & 9.7 & 2 \\
UK & 14.3 & 15.6 & 32.7 & 2.7 & $\mathrm{I}$ & 10.6 & 84 \\
USA & 9.1 & 16.4 & 174.8 & 105.1 & $\mathrm{~L} / \mathrm{D} / \mathrm{I}^{*}$ & 10.9 & 161 \\
Unknown origin & 7.78 & 15.1 & 72.2 & 2.2 & - & - & 22 \\
\hline
\end{tabular}

Notes: L - (quasi-)legalized, D - decriminalized, I - illegal. GDP $=\log$ (GDP per capita).

${ }^{*}$ State dependent.

The left-hand graph of Figure 2 shows the relationship between (log) prices and $(\log )$ quantities. Although there is a wide dispersion in prices and quantities there is a clear negative association between the two, i.e. larger quantities were offered at lower prices. The right-hand graph of Figure 2 plots cannabis prices against 
estimated THC-content. There does not seem to be a systematic relationship between these two variables.
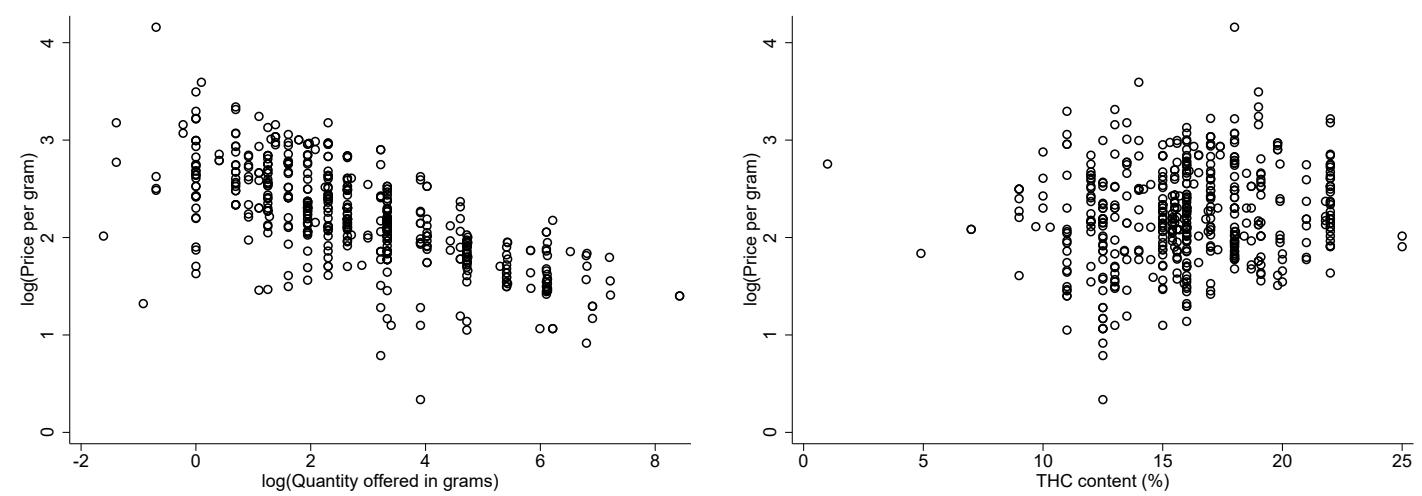

\section{Figure 2: Cannabis Prices and Quantities Per Offer; Cannabis PRICES AND THC CONTENT}

Figure 3 shows kernel densities of cannabis prices. The left-hand side graph makes a distinction according to the quality judgment from the Cannabis Cup. There is a wide dispersion in cannabis prices but the distribution of Cannabis Cup top 3 transactions is clearly shifted somewhat to the right. The right-hand side of Figure 3 makes a distinction between cannabis sold from countries where cannabis is legalized or decriminalized and countries where cannabis use is illegal. Again, there is a wide dispersion but from countries where cannabis is still an illicit drug on average cannabis prices were substantially higher.

\section{Determinants of cannabis prices}

Studies on the determinants of drug prices go back to Brown and Siverman (1974) who use a price equation with a multiplicative functional form, i.e. linear in log prices, log quantities and other variables. This example is followed in many later studies. Brown and Siverman (1974) relate US heroin prices to quantity and purity of the purchases. The finding of a negative effect of transaction quantity on 

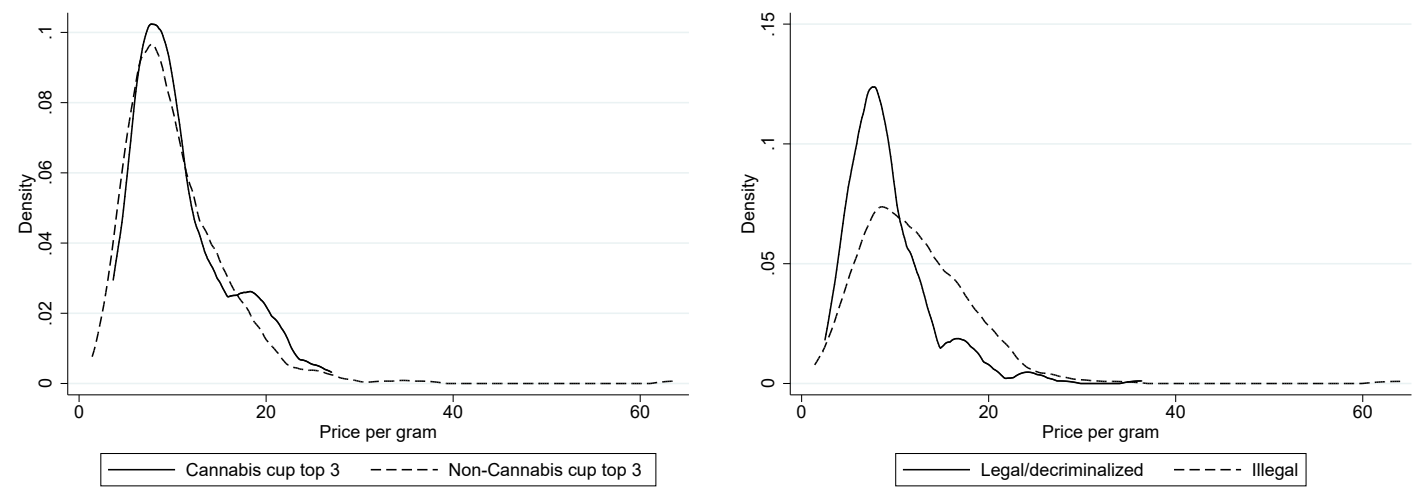

Figure 3: Kernel Densities of Cannabis Prices; By Cannabis Cup Ranking and Legal Status in the Country of Origin

price is related to the usual quantity discount but also related to the risk for the seller due to the illegal nature of the heroin market. Sellers prefer to reduce the number of risky transactions and are therefore willing to offer a discount for a large transaction. Purity of the heroin is found to have a positive effect on the price of heroin. Caulkins and Padman (1993) also analyze US price data not just for heroin but also for methamphetamine, cocaine and cannabis. In a log-linear specification they find for most drugs prices quantity discounts and quality premiums. Due to lack of information, quality premiums for cannabis could not be investigated. There is an obvious reason for this. While the quality of heroin or cocaine is measured in a simple number, purity, for cannabis quality is not one-dimensional. Heroin and cocaine are diluted along the supply chain from wholesalers to retailers. Therefore purity is an important measure, while cannabis quality does not vary over the supply chain. For cannabis purity is not an issue but the strength in terms of active ingredients, THC (Tetrahydrocannabinol) and sometimes CBD (Cannabidiol). Clements (2006) studies Australian cannabis prices finding a quantity discount whereas due to lack of information quality could not be taken into account. Caulkins and Pacula (2006) analyze US cannabis prices. As explanatory variables in their log price equation they have log quantity and characteristics 
of the place of transactions and personal characteristics of the buyer. They find a significant quantity discount. Lakhdar et al. (2016) analyzes French cannabis prices also using information on THC content and quality as perceived by users on a scale from 1 to 10. The quality of cannabis is used as an additive variable in an equation with log price as dependent variable and log quantity among the explanatory variables. Other explanatory variables relate to personal characteristics of the cannabis users. The authors find a significant quantity discount and significant positive quality effects. Lahaie et al. (2016) study French heroine prices. In the analysis a log price equation is used with log quantity, log purity and buyer characteristics as explanatory variables. The authors find significant quantity discounts and positive purity effects. Finally, Smart et al. (2017) study cannabis prices of retail transactions from Washington state including in the analysis two quality of cannabis measures in the analysis, THC-content and CBD-content. Using a log price equation their main finding are a significant quantity discount and significant positive effects of both quality indicators. All in all, previous drug price studies conclude that there are significant quantity discounts. Sometimes, also positive quality effects are found but drugs quality is not always included in the analysis, in particular for cannabis where quality information is not always available.

In our empirical analysis, we investigate whether the cannabis market is characterized by monopolistic competition. Monopolistic competition is a product market model that has characteristics of both monopoly and competitive market. Because firms sell differentiated products they have some market power, i.e. some influence over the prices they charge.

We assume that cannabis prices are affected by quantity discounts i.e. by the quantities offered and by several offer and country characteristics. We estimate 
the following equation:

$$
\log \left(P_{i j}\right)=\alpha+\beta \log \left(q_{i j}\right)+\gamma r_{i j}+X_{i j}^{\prime} \delta+\epsilon_{i j}
$$

where $P$ is the price per gram for listing $i$ of seller $j, q$ is the quantity involved in the offer, $r$ represents a vector of quality indicators, $X$ represents a vector of seller and country characteristics, $\beta, \gamma$ and $\delta$ are (vectors of) parameters and $\epsilon_{i j}$ is an error term. The parameter $\beta$ represents the quantity discount which may be related to risk-averse behavior of the sellers but is a phenomenon that is present also for many legal goods. ${ }^{16}$

The cannabis quality characteristics we take into account in our analysis are whether or not the seller claims that the cannabis strain on offer was placed in the so called "cannabis cup top 3" and the THC content of the cannabis on offer. ${ }^{17}$ The seller rating represents the main characteristics of the seller although in one of our sensitivity analysis we include seller fixed effects to remove unobserved time-invariant differences between cannabis sellers. In addition to these offer characteristics we also investigate the effects of country characteristics which may affect cannabis prices. We use a dummy variable to represent whether the country of the seller had cannabis legalized or decriminalized assuming that if so cannabis might be cheaper for the seller to obtain. We also include average electricity prices in the country of the seller because it may be more expensive to produce cannabis in some countries than it is in others. Finally, we include GDP per capita of the country of the seller again representing that it may be more expensive to produce cannabis in a country with higher wage costs. If electricity prices and/or GDP per capita matter this is also an indication that the cannabis market is not fully

\footnotetext{
${ }^{16}$ Clements (2006) mentions that also for groceries there are quantity discounts. He presents estimates of (significant) discount elasticities ranging from -0.12 for rice to -0.42 for baked beans.

${ }^{17}$ Note that the THC content is not verified but claimed by the seller through the reported cannabis strain on offer.
} 
competitive. Our specification of the price equation suggests that the cannabis market through AlphaBay has monopolistic competition features as we include quality indicators and seller characteristics. ${ }^{18}$ If quality matters, this implies that there is product differentiation, whereas if country characteristics are important this suggests that sellers have some influence over the cannabis price they charge.

\section{$5 \quad$ Parameter Estimates}

Table 3 reports our parameter estimates. To account for the fact that we have repetitive observations per seller we cluster standard errors at the level of the seller. The upper part of the table shows the effects of the offer characteristics, the lower part of the table shows the effects of the country characteristics. For the sake of comparison, we estimate the model defined in equation (1) in its simplest form, relating prices to quantities only. This also allows us to use all 511 prices observed in the dataset. The results in column (1) show that a one percent increase in the quantity of the offer is reflected in a 0.19 percent decrease in cannabis price. This is an expected result, since a quantity discount is often used as an incentive to purchase larger quantities. It might also signal that sellers try to minimize the risk of being caught by trying to sell the stock faster. The estimated parameter of the log quantity slightly changes after we introduce other explanatory variables. Column (2) shows that cannabis prices are affected by quality as measured by the success of the particular cannabis strain in the Cannabis Cup competition. Successful cannabis strains on average have a $10 \%$ higher price. Column (2) also shows that more reliable sellers seem to charge higher prices but this effect is not

\footnotetext{
${ }^{18}$ See Crozet et al. (2012) for a study on the relationship between quality and price of French champagne wines. From a market with monopolistic competition they derive a simple linear relationship with log prices being explained by quality indicators. One of their findings is that quality increases prices monotonically. Their direct measures of quality are based on expert assessment of the quality of champagne producers as published in a champagne guide. This is similar to our measure of quality based on consumer ratings and cannabis cup ranking.
} 


\section{Table 3: Parameter Estimates of Log Cannabis Prices}

\begin{tabular}{|c|c|c|c|c|c|c|c|c|c|c|}
\hline & & $(1)$ & & $(2)$ & & $(3)$ & & $(4)$ & & $(5)$ \\
\hline \multicolumn{11}{|c|}{ Panel A: Transaction characteristics } \\
\hline $\log$ (Quantity) & -0.19 & $(10.7)^{* * *}$ & -0.18 & $(12.4)^{* * *}$ & -0.18 & $(11.7)^{* * *}$ & -0.17 & $(11.1)^{* * *}$ & -0.17 & $(7.8)^{* * *}$ \\
\hline Cannabis cup top 3 & & & 0.10 & $(2.8)^{* *}$ & 0.11 & $(3.2)^{* * *}$ & 0.13 & $(3.4)^{* * *}$ & 0.09 & $(2.6)^{* *}$ \\
\hline $\log$ (Seller rating) & & & 0.30 & $(0.9)$ & & & & & & \\
\hline $\log (\mathrm{THC}$ content $)$ & & & 0.09 & $(0.9)$ & & & & & & \\
\hline \multicolumn{11}{|c|}{ Panel B: Country characteristics } \\
\hline $\log$ (Electricity price) & & & 0.25 & $(2.3)^{* *}$ & 0.26 & $(3.7)^{* * *}$ & 0.26 & $(3.7)^{* * *}$ & & \\
\hline $\log ($ GDP per capita $)$ & & & 0.27 & $(4.4)^{* * *}$ & 0.28 & $(4.6)^{* * *}$ & 0.25 & $(5.6)^{* * *}$ & & \\
\hline Legal/decriminalized & & & -0.02 & $(0.2)$ & & & & & & \\
\hline Seller fixed effects & & No & & No & & No & & No & & Yes \\
\hline Observations & & 511 & & 479 & & 486 & & 468 & & 468 \\
\hline Sellers & & 141 & & 128 & & 130 & & 129 & & 98 \\
\hline
\end{tabular}

Notes: ${ }^{*} p<0.10,{ }^{* *} p<0.05,{ }^{* * *} p<0.001$

Constant not reported. Absolute $t$ statistics in parentheses. Standard errors clustered at the level of the seller.

Column (4): top $1 \%$ and bottom $1 \%$ of prices \& quantities are removed.

significantly different from zero. It could be that there is insufficient variation in seller rating with about two-thirds of the sellers receiving only positive ratings (and therefore have a score of 100). Also, the relationship between the strength of the cannabis herb and the price is not different from zero at conventional levels of significance. This may have to do with not all listings providing information about the THC-content. For those listing that did not provide this information we calculated the THC-content on the basis of information about the particular strain of cannabis on sale.

The estimates in column (2) of Table 3 also include some country characteristics. Cannabis is usually produced indoors, which requires significant amounts of electricity to power lamps used as a substitute for natural sunlight. Several factors influence the yield of cannabis plants, most notably the number of plants per lighting lamp. Under ideal indoor conditions, a $600 \mathrm{~W}$ lamp used on four plants yields roughly 135-150 grams of dried cannabis per plant. Electricity therefore enters as an important production factor. Apart from high-intensity lighting, significant amounts of energy are also used for dehumidification to remove water vapor, space 
heating or cooling, drying, pre-heating of irrigation water, generation of carbon dioxide by burning fossil fuel, and also ventilation to remove waste heat. According to Caulkins (2010), the electricity generated by lamps accounts for 75 of the 200-400 US dollars cost per pound of indoor production. Our results suggest that indeed, higher electricity prices are also reflected in cannabis prices. There is a significant positive relationship between GDP per capita and cannabis prices. As discussed earlier, there is a shift towards more liberal cannabis policies around the world. Access to cannabis in countries or states where it is legal or decriminalized is obviously easier. This in turn could affect the price and supply, as potential risk of being caught is smaller. The coefficient of the dummy variable for the legal status of cannabis suggests that sellers from countries where cannabis is legal or decriminalized charge lower prices compared to countries where the possession of the herb is illegal. However, the parameter estimate is not significantly different from zero.

As a sensitivity analysis, column (3) of Table 3 shows the parameter estimates after three insignificant variables are excluded from the analysis. The remaining parameter estimates hardly change. Column (4) shows that the parameter estimates also hardly change if we remove the top one percent and bottom one percent of the cannabis prices as well as the top one percent and bottom one percent of transaction quantities from the sample. Finally, in column (5) we present the parameter estimates in a seller fixed effects specification of the model defined in equation (1). The quantity discount parameter is hardly affected. The effect of winning the Cannabis cup is slightly reduced but still significantly different from zero.

Our estimate of the quantity discount elasticity of -0.19 is very much in line with previous studies. Caulkins and Padman (1993) report and quantity discount elasticity of -0.23 for cannabis sold in the US, Clements (2006) finds a quantity 
discount elasticity of -0.25 for cannabis sold in Australia. Caulkins and Pacula (2006) find a quantity discount elasticity of -0.58 for cannabis sold in the US. Lakhdar et al. (2016) find a quantity discount elasticity for cannabis sold in France of -0.21. Smart et al. (2017) find a quantity discount elasticity of -0.07 for cannabis sold in Washington state. Caulkins and Pacula (2006) suggest that their high (absolute) quantity discount elasticity compared to other studies may be related to other studies not taking potency into account. The quantity discount elasticities are also similar for prices of other illegal drugs. Brown and Siverman (1974) find an estimate for heroin sold in the US of about -0.26. Caulkins and Padman (1993) analyzing US data present quantity discount parameter estimates of -0.21 for methamphetamine, -0.17 for cocaine and -0.16 for heroin. Lahaie et al. (2016) find a quantity discount elasticity for heroin sold in France of -0.23.

As Caulkins and Padman (1993) note, the distribution network for illicit drugs is often hierarchical, where drugs are re-packaged by mid-dealers at various stages of the network which may increase the price of the original purchase. Also, transportation costs for trafficking might be reflected in the price. Therefore, it could be that the further the final seller is from the trafficking source, the higher the cannabis price will be. We also included the distance to the trafficking source. We find no significant effects. The explanations for this are twofold. First, cannabis can be produced indoors and its production is not as geographically dependent as with, for example, cocaine. Therefore, it is likely that sellers on the Dark Web either grow cannabis themselves, or are already close to the source of production. Second, the hierarchical model of the distribution network does not apply for cannabis, a possibility also noted by Caulkins and Padman (1993). Finally, as noted before, the nature of the Dark Web introduces opportunities for a scam. Therefore, the vast majority of sellers used escrow payments. Since the transaction was usually finalized by the customer upon arrival of the goods, there was a 
possible risk for sellers that the package was intercepted by the authorities. This risk might be reflected in higher prices. However, we do not find a significant effect of the payment method on cannabis prices.

\section{Conclusions}

It is possible to buy and sell illegal drugs in a rather anonymous way through internet. Improvements in the internet security over the past decade transitioned a small proportion of black markets to the already popular and fast-growing ecommerce. Thanks to the highly sophisticated cryptographic algorithms and a user-friendly platform, the almost untraceable nature of the network on the Dark Web allows users to safely engage in trade of illicit drugs. Compared to traditional street transactions, several Dark Web sites allow sellers to easily enter the international market. This implies that the Dark Web market for drugs is different from usual drug markets. In regular drug markets there may be infrequent interactions between sellers and buyers in which cause buyers cannot be sure of the quality of the drug they bought. In online markets, sellers who do not live up to their promises may receive bad ratings and face serious drops in sales. Through internet, compared to street level transactions consumers can buy their drugs in a relatively safe environment. Nevertheless, there are also consumers who have repeated transactions of drugs in which case they have more control over the quality. Also, quite a few drugs transactions are made within friendship networks. For consumers who have repeated transactions and friendship networks the Dark Web has little to offer.

Our paper presents an analysis on the supply side investigating the determinants of cannabis prices. Like previous studies, we investigate how cannabis prices are affected by quantity discounts and by quality of the cannabis for sale. Our 
analysis is based on unique data on cannabis prices. Whereas usually information on cannabis prices is based on undercover operations or consumer surveys we use information from cannabis sellers, exploiting data from the Dark Web site called AlphaBay. Our data allow us to include in the analysis seller characteristics including country of residence. In all model specifications, we find a precisely estimated quantity discount offered by sellers. Cannabis prices are lower if sold in larger quantities, which is in line with usual quantity discounts but could also be at least partly related to risk-averse behavior of the seller. We also find that both listing characteristics and country characteristics matter. We find clear evidence for quality premiums measured by the popularity of the particular cannabis strain. We also find cannabis prices to be higher in countries with higher electricity prices and a higher GDP per capita. From this, we conclude that the internet based cannabis market seems to be characterized by monopolistic competition where many sellers offer differentiated products with quality variation causing a dispersion of cannabis prices and sellers have some control over the cannabis prices. 


\section{References}

Aldridge, J. and D. Décary-Hétu (2016). Hidden wholesale: The drug diffusing capacity of online drug cryptomarkets. International Journal of Drug Policy 35, 7-15.

Aldridge, J., A. Stevens, and M. J. Barratt (2018). Will growth in cryptomarket drug buying increase the harms of illicit drugs? Addiction 113, 789-796.

Barratt, M. J. and J. Aldridge (2016). Everything you always wanted to know about drug cryptomarkets (but were afraid to ask). International Journal of Drug Policy 35, $1-6$.

Barratt, M. J., J. A. Ferris, and A. R. Winstock (2014). Use of Silk Road, the online drug marketplace, in the United Kingdom, Australia and the United States. Addiction 109(5), 774-783.

Bhaskar, V., R. Linacre, and S. Machin (2019). The economic functioning of online drugs markets. Journal of Economic Behavior \& Organization 159, 426-441.

Brown, G. F. and L. P. Siverman (1974). The retail price of heroin: Estimation and applications. Journal of the American Statistical Association 69(347), 595-606.

Cameron, L. and J. Williams (2001). Marijuana, alcohol, and cigarettes: Substitutes or complements? Economic Record 7r, 19-34.

Caulkins, J. P. (2010). Estimated cost of production for legalized cannabis. Working Paper Series RAND Drug Policy Research Center.

Caulkins, J. P. and R. L. Pacula (2006). Marijuana markets: Inferences from reports by the household population. Journal of Drug Issues 36(1), 173-200.

Caulkins, J. P. and R. Padman (1993). Quantity discounts and quality premia for illicit drugs. Journal of the American Statistical Association 88(423), 748-757.

Christin, N. (2017). An EU-focused analysis of drug supply on the AlphaBay marketplace. European Monitoring Centre for Drugs and Drug Addiction.

Clements, K. W. (2006). Pricing and packaging: The case of marijuana. Journal of Business 79(4), 2019-2044.

Clements, K. W., Y. Lan, and X. Zhao (2010). The demand for marijuana, tobacco and alcohol: Inter-commodity interactions with uncertainty. Empirical Economics 39(1), 203-239.

Clements, K. W. and X. Zhao (2009). Economics and marijuana: Consumption, pricing and legislation. Cambridge University Press, Cambridge. 
Crozet, M., K. Head, and T. Mayer (2012). Quality sorting and trade: Firm-level evidence for French wine. Review of Economic Studies 79, 609-644.

Décary-Hétu, D., M. Paquet-Clouston, and J. Aldridge (2016). Going international? Risk taking by cryptomarket drug vendors. International Journal of Drug Policy 35, $69-76$.

DeSimone, J. and M. Farrelly (2003). Price and enforcement effects on cocaine and marijuana demand. Economic Inquiry 41, 98-115.

Duxbury, S. W. and D. L. Haynie (2018). The network structure of opioid distribution on a darknet cryptomarket. Journal of Quantitative Criminology 34(4), 921-941.

Jikomes, N. and M. Zoorob (2018). The cannabinoid content of legal cannabis in Washington state varies systematically across testing facilities and popular consumer products. Scientific Reports 8, 1-15.

Lahaie, E., E. Janssen, and A. Cadet-taïrou (2016). Determinants of heroin retail prices in metropolitan France: Discounts, purity and local markets. Drug and Alcohol Review 35, 597-604.

Lakhdar, C. B., N. G. Vaillant, and F.-C. Wolff (2016). Price elasticity of demand for cannabis: Does potency matter? Addiction Research and Theory 24(4), 300-312.

McCoy, D., K. Bauer, D. Grunwald, T. Kohno, and D. Sicker (2008). Shining light in dark places: Understanding the TOR Network. In N. Borisov and I. Goldberg (Eds.), Privacy Enhancing Technologies, Volume 5134 of Lecture Notes in Computer Science, pp. 63-76. Springer Berlin Heidelberg.

Nisbet, C. T. and F. Vakil (1972). Some estimates of price and expenditure elasticities of demand for marijuana among UCLA students. Review of Economics and Statistics 54 (4), 473-475.

Pacula, R. L., M. Grossman, F. J. Chaloupka, P. M. O'Malley, L. Johnston, and M. C. Farrelly (2001). Marijuana and youth. In G. J. (Ed.), Risky behavior among youths: An economic analysis, pp. 271-326. University of Chicago Press.

Paquet-Clouston, M., D. Décary-Hétu, and C. Morselli (2018). Assessing market competition and vendors' size and scope on alphabay. International Journal of Drug Policy 54, 87-98.

Smart, R., J. P. Caulkins, B. Kilmer, S. Davenport, and G. Midgette (2017). Variation in cannabis potency and prices in a newly legal market: evidence from 30 million cannabis sales in Washington state. Addiction 112(12), 2167-2177. 
Soaka, K. and N. Christin (2015). Measuring the longitudinal evolution of the online anonymous marketplace ecosystem. In Proceedings of the 25th USENIX Security Symposium.

United Nations Office on Drugs and Crime (2018). World Drug Report 2018. Vienna: United Nations.

Van Hout, M. C. and T. Bingham (2013). Surfing the Silk Road: A study of users' experiences. International Journal of Drug Policy 24, 524-529.

Van Ours, J. C. and J. Williams (2007). Cannabis prices and dynamics of cannabis use. Journal of Health Economics 26, 578-596.

Williams, J. (2004). The effects of price and policy on marijuana use: What can be learned from the Australian experience? Health Economics 13, 123-137.

Williams, J., R. L. Pacula, F. J. Chaloupka, and H. Wechsler (2004). Alcohol and marijuana use among college students: Economic complements or substitutes? Health Economics 13(9), 825-843.

Zhao, X. and M. Harris (2004). Demand for marijuana, alcohol and tobacco: Participation, levels of consumption and crossequation correlations. Economic Record 80, $359-482$. 


\section{Appendix A}

\section{A.1 Definition of variables}

- Cannabis price: Price per gram of cannabis of the respective listing in US $\$$.

- Quantity sold: Quantity of cannabis offered for the respective listing.

- Seller rating: Percentage of positive ratings in all seller ratings (positive, neutral or negative); scale 0 to 100 .

- Escrow payment: Dummy variable if a transaction had to be verified by a trusted third party (site administrator).

- THC content: Average content of the active psychoactive ingredient in cannabis for the particular cannabis strain. Since the THC content usually varies even within the same strain, most laboratories provide the average content collected from several tests. If not included in the listing description, the data were obtained from following sites: http://www.leafly.com, http://analytical360.com/ testresults, https://budgenius.com/strains.html, http://www.wikileaf . com. We calculate the THC content of the strain as an average of all available test results and the value claimed by the seller.

- Top 3 cannabis cup: Dummy variable indicating whether the particular strain was placed in the top 3 of the High Times Cannabis cup. The Cannabis cup is an annual exhibition and festival of cannabis products, taking place in Amsterdam since 1988. Starting in 2010, the Cannabis cup is also organized in the United States. See: http://www. cannabiscup.com/

- Decriminalized/legal: Dummy variable indicating if cannabis is legal or decriminalized in the country of the seller.

- Distance to source: Point-to-point distance in kilometers from the geographical mid-points of the country of the seller and the main trafficking source coun- 
try. Based upon UNODC World Drug reports. Calculated using https://www . freemaptools.com/how-far-is-it-between.htm.

- Electricity cost: Average price per kilowatt hour (in US dollar cents) in the country of the seller. Source: Eurostat, IEA World Energy Outlook.

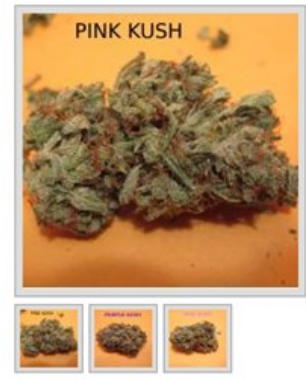

FB's MED. WEED - PURPLE KUSH (8.5/10) \& PINK KUSH (9/10) [7 GRAMS]

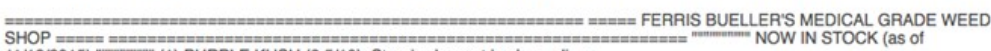

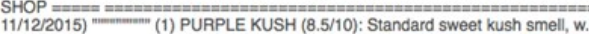

Sold by ferrisbueller - 164 sold since May 23, 2015 Vendor Level 3 Trust Level 4

$\begin{array}{llll} & \text { Features } & \text { Foatures } \\ \text { Product class } & \text { Physical package } & \text { Origin country } & \text { Canada }\end{array}$

Quantity left Unlimited $\quad$ Ships to $\quad$ Worldwide

$\begin{array}{llll} & \text { Unlimited } & \text { Ships to } & \text { Worldwide } \\ \text { Ends in } & \text { Never } & \text { Payment } & \text { Escrow }\end{array}$

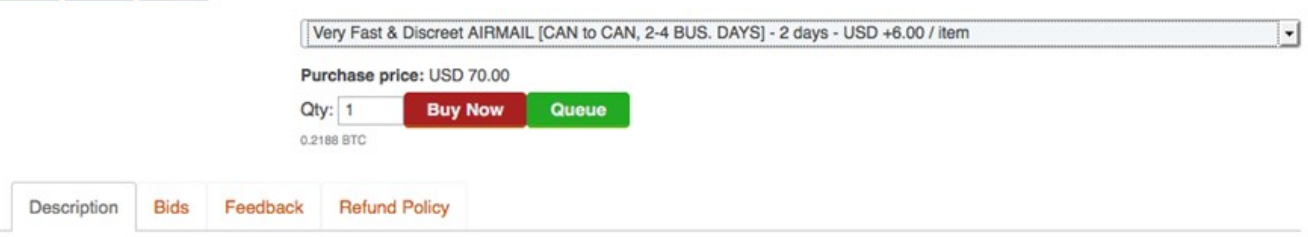

Figure A1: Example AlphaBay Listing 